\title{
AB (TYPE V) AND BASEMENT MEMBRANE (TYPE IV) COLLAGENS IN THE BOVINE LUNG PARENCHYMA: ELECTRON MICROSCOPIC LOCALIZATION BY THE PEROXIDASE-LABELED ANTIBODY METHOD
}

\author{
JUNJIRO SANO ${ }^{1}$, SAKUHEI FUJIWARA, SHIGERU SATO*, MASAMICHI ISHIZAKI*, \\ YUICHI SUGISAKI*, GONPACHI YAJIMA* and YUTAKA NAGAI ${ }^{2}$ \\ Department of Tissue Physiology, Medical Research Institute, Tokyo Medical and Dental University, Kanda- \\ surugadai, Tokyo 101, and *The First Department of Pathology, Nippon Medical School, Sendagi, Tokyo \\ 113, Japan
}

\begin{abstract}
The microdistribution of $\mathrm{AB}$ collagen and basement membrane (type IV) collagen in the bovine lung parenchyma has been studied by the immunoelectron microscopic method.

$A B$ collagen was isolated from the pepsin digests of bovine lung parenchyma and purified with differential salt fractionation. Identification and purity of the collagen were assessed by SDS-polyacrylamide gel electrophoresis, collagenase digestion, phosphocellulose chromatography, amino acid analysis and by electrophoresis of CNBr-cleavage products.

Type specific rabbit antibodies to $\mathrm{AB}$ and type IV collagens showing no crossreaction with other types of collagen were prepared by the immunoadsorption technique.

Immunoelectron microscopic studies using the indirect peroxidase-labeled antibody method have shown that $A B$ collagen is located on the surfaces of varied cells, such as bronchiolar and alveolar epithelial cells, vascular endothelial cells and alveolar septal cells. On the other hand, type IV collagen is located along basement membranes of alveoli and capillaries.
\end{abstract}

KEY WORDS antibody/basement membrane/collagen / immunoelectron microscopy / lung parenchyma

The molecular heterogeneity of collagen is now well established (7) and at least five genetically distinct collagens (type $\mathrm{I}-\mathrm{V}$ ) have been identified in mammalian tissues. Type I-III collagens are present in the interstitium, and the basement

1. Present address: The First Department of Pathology, Nippon Medical School, Sendagi, Tokyo 113

2. Reprint request to Y. Nagai, Department of Tissue Physiology, Medical Research Institute, Tokyo Medical and Dental University, Kandasurugadai 2-3-10, Chiyodaku, Tokyo 101, Japan membrane (type IV) collagen is present only in basement membranes.

$A B$ (type $V$ ) collagen was first isolated from human placental tissues by Burgeson et al. in 1976 (4). Thereafter, AB collagen has been identified in many tissues such as vessel walls (5), bone and cartilage (22), skeletal muscle (6), cornea and skin (10), synovia (3), lungs (14), and tendons (12). However, its molecular structure and tissue localization still remain to be elucidated, although both would provide key items of information about the physiological function of this collagen. 
Burgeson et al. (4) first emphasized that $\mathrm{AB}$ collagen was extracted from basement membranerich tissues such as placenta. However, the contents in tissues of $\mathrm{AB}$ collagen may not be related to those of basement membranes in situ, since the collagen was also found in cartilage.

Another approach which may help to clarify the tissue localization of $\mathrm{AB}$ collagen is the use of the immunohistological technique. Furthmayr et al. reported the codistribution of type IV and $\mathrm{AB}$ collagens in the basement membranes of human lungs and murine kidneys, based on double label indirect immunofluorescence staining (15) and immunoferritin labeling of ultrathin frozen sections (23). In addition, McCullagh et al. (17) and Pöschl and von der Mark (21) reported on the basis of immunofluorescence studies that $\mathrm{AB}$ collagen might also form part of the interstitial extracellular matrix.

In investigating tissue localizations of collagen types by using antibodies to individual types of collagen, the purity of the antigens and the cross-reactivity of the antibodies with other types of collagen might affect the results obtained. Furthermore, analysis by the immunofluorescence light microscopic method may not give much information on the microdistribution in tissues of collagen types. Therefore, we aimed to elucidate the relation between $A B$ collagen and type IV collagen in terms of tissue localizations by using an immunoelectron microscopic technique with antibodies type-specific to $\mathrm{AB}$ and type IV collagens, which were isolated and purified from bovine lung lobules and glomerular basement membranes, respectively.

\section{MATERIALS AND METHODS}

\section{Isolation of Collagens}

All procedures for collagen isolation were performed at $4-10^{\circ} \mathrm{C}$ otherwise stated. $\mathrm{AB}$ collagen was isolated from the bovine lung tissue. Fresh bovine lungs were obtained from a local slaughterhouse. Pulmonary lobules were separated manually from the tracheobronchial tissue on ice to minimize the contamination of bronchial cartilage. The collected lobules were washed extensively for one week with several changes of distilled water containing $4 \mathrm{mM}$ EDTA, $2 \mathrm{mM}$ phenylmethylsulfonyl fuuoride and $10 \mathrm{mM} N$-ethylmaleimide and then homogenized three times in chilled distilled water with a VirTis homogenizer (Model No. $60 \mathrm{~K}$, Gardiner, $\mathrm{NY}$ ) at $30,000 \mathrm{rpm}$ for $30 \mathrm{sec}$ and again washed extensively with distilled water. The homogenate was then incubated for $24 \mathrm{hr}$ with pepsin
( $1 \mathrm{~g} / 20 \mathrm{~g}$ dry weight tissue, Worthington Biochemical Corp., Freehold, New Jersey). The undigested residue was removed by centrifugation, then $\mathrm{AB}$ collagen was isolated and purified from the supernatant, as described by Rhodes and Miller (22), with the exception that at the final step of purification, $\mathrm{AB}$ collagen was precipitated by dialysis against $0.1 \mathrm{M} \mathrm{NaCl} / 0.05$ $\mathrm{M}$ Tris- $\mathrm{HCl}$ buffer, $\mathrm{pH} 7.4$, instead of dialyzing against $0.01 \mathrm{M}$ Tris- $\mathrm{HCl}$ buffer, $\mathrm{pH} 8.6$, containing $0.02 \mathrm{M} \mathrm{NaCl}$ and $2.0 \mathrm{M}$ urea. The precipitate was collected by centrifugation, redissolved in $0.5 \mathrm{M}$ acetic acid, dialyzed extensively against distilled water and lyophilized.

Type IV collagen was isolated from bovine glomerular basement membranes as described previously (19). Type I and type III collagens (from fetal calf skin) and type II collagen (from bovine articular cartilage) were prepared in a recent study (13).

\section{Analytical Methods}

SDS-polyacrylamide gel electrophoresis of collagen chains and their cyanogen bromide cleavage-peptides was carried out in $5 \%$ and $15 \%$ separating gels, respectively, as reported (8).

Bacterial and animal collagenase digestion was performed using purified $\mathrm{Cl}$. histolyticum collagenase (Amano Pharmaceutical Co., Ltd., Nagoya) (20) and tadpole skin collagenase (11). Phosphocellulose chromatography of $\mathrm{AB}$ collagen was carried out as described by Rhodes and Miller (22). Amino acid analysis of AB collagen and its $\alpha$-chains was performed using a JEOL model 6AS amino acid autoanalyzer after hydrolysis with $6 \mathrm{M} \mathrm{HCl}$ in an evacuated sealed tube at $110^{\circ} \mathrm{C}$ for $24 \mathrm{hr}$.

\section{Preparation of Antisera and Type-Specific Antibodies}

Rabbits were immunized with the $\mathrm{AB}$ collagen isolated from bovine lung parenchyma. The initial injection was given intradermally with 2 $\mathrm{mg}$ of the antigen which was dissolved in $5 \mathrm{mM}$ acetic acid and emulsified with an equal volume of Freund's complete adjuvant (DIFCO Laboratories, Detroit, Michigan). Four and six weeks after the initial injection, intradermal booster injections of $1 \mathrm{mg}$ of the antigen in $5 \mathrm{mM}$ acetic acid were administered. Blood was collected and serum was separated 10 weeks after the initial immunization. The antibodies against $A B$ collagen were purified by immunoadsorption on an affinity column composed of the antigen 
(AB collagen) conjugated to $\mathrm{CNBr}$-activated Sepharose 4B (16). The specific anti-AB collagen antibodies were eluted with $3 \mathrm{M} \mathrm{NaSCN} /$ $0.05 \mathrm{M}$ Tris- $\mathrm{HCl}$ buffer, $\mathrm{pH} 7.4$, containing 0.15 $\mathrm{M} \mathrm{NaCl}$ followed by $0.1 \mathrm{M}$ glycine- $\mathrm{HCl}$ buffer, $\mathrm{pH} 2.8$, then dialyzed against $0.15 \mathrm{M} \mathrm{NaCl} / 0.05$ $\mathrm{M}$ Tris- $\mathrm{HCl}$ buffer, $\mathrm{pH} 7.5$ (2), and concentrated to a $1 / 6$ volume of the antiserum loaded on the column by ultrafiltration using an Amicon Diaflo UM-10 membrane (Amicon Co., Lexington, Mass.). The antibodies to type IV collagen were prepared in a recent study (13).

\section{Passive Hemagglutination Assay and Double Diffusion Test}

The titers of purified antibodies and cross reactivity against other types of collagen were determined using the passive hemagglutination assay as described by Herbert (9). A suspension of fresh sheep red blood cells coated with bovine Type I, II, III, IV or AB collagen and of cells with an $\alpha$ A-chain or an $\alpha$ B-chain $(0.5 \%, 25 \mu \mathrm{l})$ was incubated overnight at room temperature with $25 \mu \mathrm{l}$ of a series of dilution of anti-AB collagen antibody. The antibodies to type IV and $A B$ collagens were examined by means of the double diffusion test using goat antibodies to rabbit serum, IgG or IgM.

\section{Immunoelectron Microscopy}

Immunoelectron microscopy by the indirect peroxidase-labeled antibody method was performed as described by Yamada and Nakane (26). Fresh bovine lung specimens obtained from a local slaughterhouse were immediately fixed with periodate-lysine-paraformaldehyde fixative (PLP) $\left(0.01 \mathrm{M} \mathrm{NaIO}_{4}, 0.075 \mathrm{M}\right.$ lysine, $0.0375 \mathrm{M}$ sodium phosphate buffer, $2 \%$ paraformaldehyde) for $6 \mathrm{hr}$. They were then washed overnight in $0.05 \mathrm{M}$ sodium phosphate buffer, pH 7.4, (PBS) with 10\% sucrose, PBS with $15 \%$ sucrose for $12 \mathrm{hr}$ and PBS with 15\% sucrose and $10 \%$ glycerol for $2 \mathrm{hr}$. The resulting tissues were embedded in OCT compounds (Lab-Tek Products, Napaville, Illinois) with $10 \%$ glycerol, quick-frozen in liquid nitrogen and stored at $-70^{\circ} \mathrm{C}$. The $4 \mu \mathrm{m}$ frozen sections cut in a cryostat were mounted on glass slides coated with egg albumin and washed three times in PBS with $10 \%$ sucrose. For indirect immunohistochemical staining, the tissue sections were incubated at $4^{\circ} \mathrm{C}$ overnight with antibodies to type IV collagen or AB collagen.

The tissue sections were washed with PBS containing $10 \%$ sucrose eight times at $4^{\circ} \mathrm{C}$ for $12 \mathrm{hr}$, then incubated at $4^{\circ} \mathrm{C}$ overnight with horseradish peroxidase (HRPO)-labeled antirabbit IgG goat antibodies (Miles Laboratories, Inc., Elkhart, Indiana) diluted 1:16 with the buffer. The tissue sections were washed eight times at $4^{\circ} \mathrm{C}$ for $12 \mathrm{hr}$ with the buffer. After postfixation in $2 \%$ glutalaldehyde for $20 \mathrm{~min}$, they were reacted with $0.02 \%$ diaminobenzidine

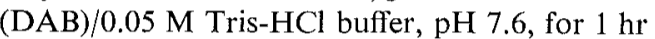
and with DAB with $0.005 \%$ peroxide for several min. They were then fixed in $2 \%$ osmium tetroxide for $30 \mathrm{~min}$, dehydrated in graded series of ethanol to $100 \%$ and finally embedded in a capsule of SPUR (Polysciences, Inc., Warrington, Pennsylvania). The blocks were examined by light microscopy to select positively stained areas. Ultrathin sections of these areas were cut on a LKB ultramicrotome and observed without additional staining or with uranyl acetate staining under a Hitachi 12A electron microscope. As controls, tissue sections were incubated with antibodies preincubated with $\mathrm{AB}$ collagen (2 $\mathrm{mg} / \mathrm{ml}$ ) at $4^{\circ} \mathrm{C}$ overnight or incubated with normal rabbit serum diluted 1:16 with PBS containing $10 \%$ sucrose.

\section{RESULTS AND DISCUSSION}

\section{Chemical Studies}

$\mathrm{AB}$ collagen was identified and its purity assessed by SDS-polyacrylamide gel electrophoresis, collagenase digestion, phosphocellulose chromatography, amino acid analysis and by gel electrophoresis patterns of its $\mathrm{CNBr}$-cleavage products. The collagen preparation precipitated at $0.1 \mathrm{M} \mathrm{NaCl}$ concentration/Tris- $\mathrm{HCl}$ buffer, pH 7.4, (see Materials and Methods) contained only $\mathrm{AB}$ collagen. Typical electrophoretic profiles of the $0.1 \mathrm{M} \mathrm{NaCl}$ precipitate before and after reduction with dithiothreitol are shown in Fig. 1, channels 2 and 3, respectively; as described by Burgeson et al. (4), its mobility was unaffected by the presence of disulfide-reducing reagent. Digestion of the material with $\mathrm{Cl}$. histolyticum collagenase resulted in the complete hydrolysis (Fig. 1, channel 4).

As reported (24), the collagenous material was resistant to the action of tadpole collagenase under the conditions where Type I and II collagens were digested about $95 \%$ and $80 \%$, respectively (data not shown). When the collagen was heat-denatured and chromatographed on a phosphocellulose column, it was resolved into two components which were eluted out in the fractions corresponding to $\alpha \mathrm{A}$ - and $\alpha \mathrm{B}$-chains as 


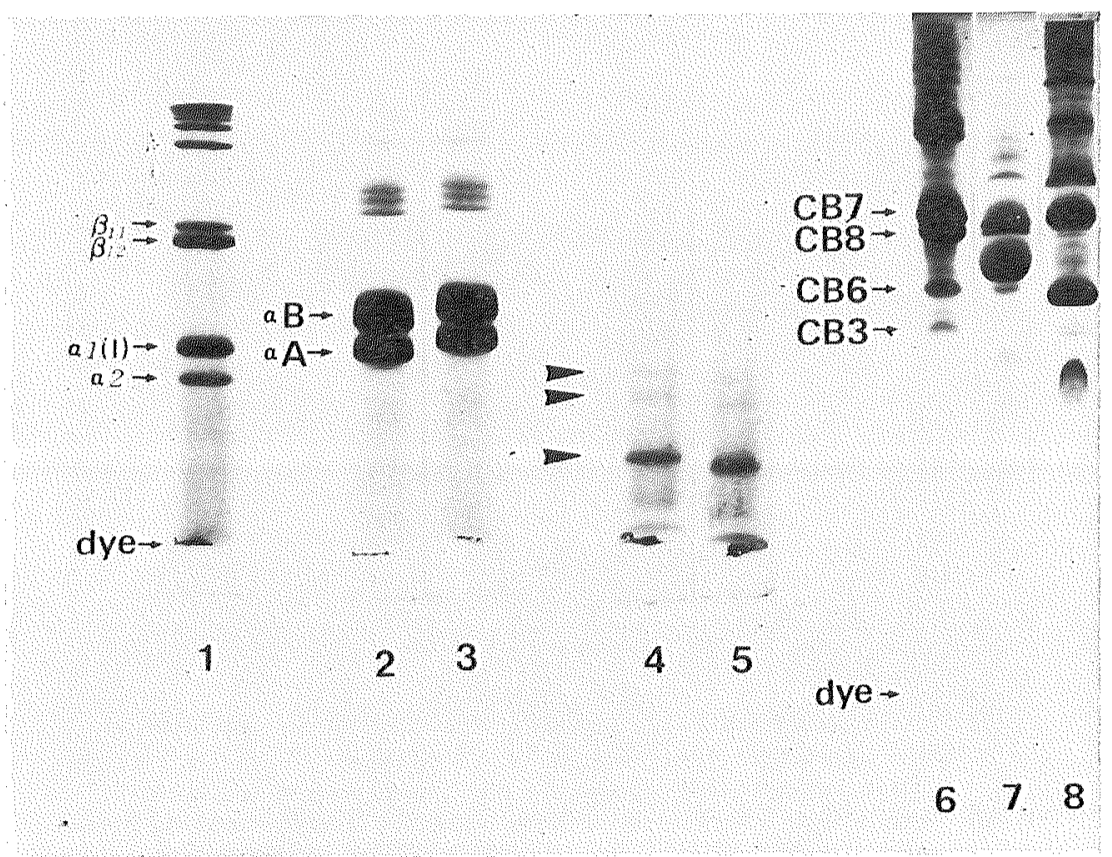

Fig. 1 SDS-polyacrylamide gel electrophoresis patterns of $\mathrm{AB}$ collagen and its bacterial collagenase digests and $\mathrm{CNBr}$-cleavage products. $5 \%$ gel (1-5) and 15\% gel (6-8). Calf skin type I collagen as control (1), $\mathrm{AB}$ collagen $(0.1 \mathrm{M} \mathrm{NaCl}$ precipitate, see text) before (2) and after (3) reduction with dithiothreitol, $A B$ collagen after bacterial collagenase treatment (4) and the enzyme alone (5) and $\mathrm{CNBr}$-cleavage products of rat $\alpha_{1}^{\prime}(\mathrm{I})$ - (6), bovine $\alpha \mathrm{A}-(7)$ and $\alpha$ B-chains (8). The arrowheads indicate the protein components derived from collagenase preparation. $\mathrm{CB}$ : $\mathrm{CNBr}$

described by Rhodes and Miller (22) (Fig. 2). SDS-polyacrylamide gel electrophoresis patterns of these components were quite similar to those of $\alpha \mathrm{A}$ - and $\alpha \mathrm{B}$-chains, respectively (Fig. $2 \mathrm{~b}$, channels 1-3), although a minor component corresponding to an $\alpha \mathrm{C}$-chain (24) was coeluted in the first half of the $\alpha \mathrm{A}$-chain fraction. No effluent fractions contained either type IV collagen or its subcomponents, based on SDSpolyacrylamide gel electrophoresis.

Table 1 shows the amino acid composition of the collagen and its two components isolated by chromatography. All the samples contained high amounts of glycine, proline, hydroxyproline and hydroxylysine which were typical of collagen, but showed a difference in the amounts of alanine, arginine, valine, leucine and isoleucine from all other types of collagen. The results were quite similar to those reported by Burgeson et al. (4). Gel electrophoresis patterns of the $\mathrm{CNBr}$-cleavage products of the chromatographically isolated components (Fig. 1, channels 7 and 8) were quite similar to those of $\alpha \mathrm{A}$ and $\alpha \mathrm{B}$-chains reported (24), but different from those of type IV collagen (data not shown). The results described above indicate that the
Table 1 The Amino Acid Composition of AB Collagen and its $\alpha$-Chains from Bovine Lung (Residues/ 1000 Residues)

\begin{tabular}{lcrr}
\hline Amino acid & AB collagen & $\alpha$ A & $\alpha$ B \\
\hline 3-Hyp & 4 & 4 & 5 \\
4-Hyp & 113 & 103 & 103 \\
Asp & 48 & 50 & 51 \\
Thr & 23 & 30 & 23 \\
Ser & 26 & 43 & 32 \\
Glu & 93 & 89 & 100 \\
Pro & 115 & 97 & 114 \\
Gly & 333 & 321 & 323 \\
Ala & 41 & 57 & 41 \\
1/2Cys & ND & 1 & ND \\
Val & 24 & 35 & 21 \\
Met & 12 & 14 & 12 \\
Ile & 17 & 13 & 20 \\
Leu & 38 & 36 & 39 \\
Tyr & 2 & 2 & 3 \\
Phe & 12 & 11 & 12 \\
His & 6 & 10 & 6 \\
Hyl & 35 & 19 & 40 \\
Lys & 14 & 16 & 16 \\
Arg & 44 & 49 & 39 \\
\hline
\end{tabular}

ND: not detected 


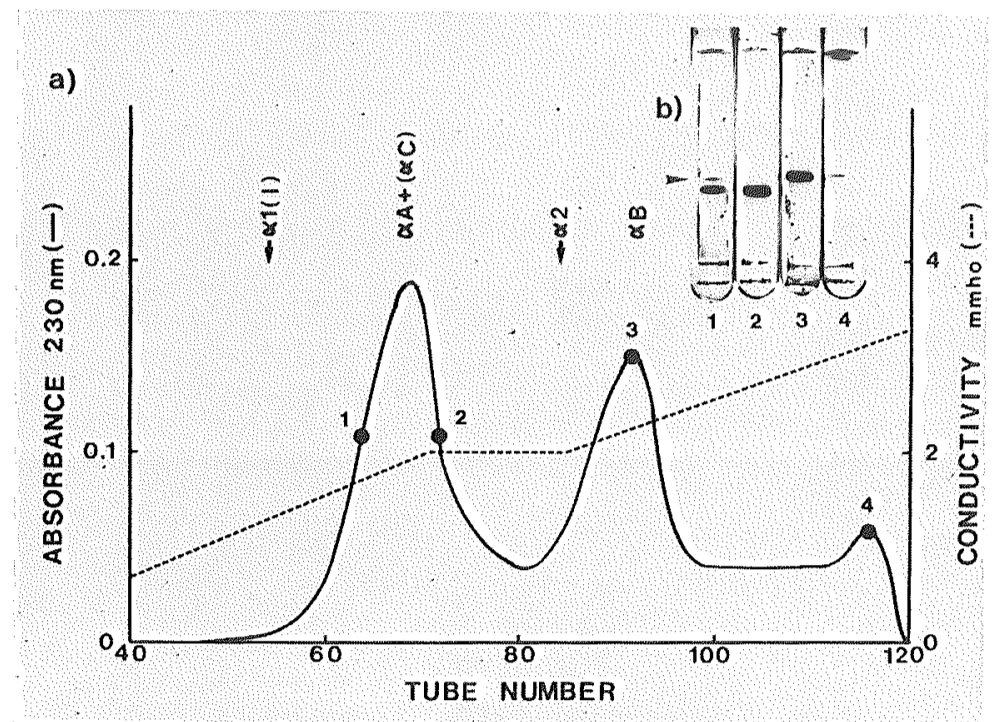

Fig. 2 Phosphocellulose chromatogram of $\mathrm{AB}$ collagen $(0.1 \mathrm{M} \mathrm{NaCl}$ precipitate), a) Heat-denatured $\mathrm{AB}$ collagen $(16 \mathrm{mg})$ was applied on a column $(1.5 \times$ $10 \mathrm{~cm})$. The arrows indicate the elution positions of $\alpha_{1}(\mathrm{I})-$ and $\alpha_{2}$-chains. b) SDS-polyacrylamide gel $(5 \%)$ electrophoresis of four different effluent fractions. Gel numbers correspond to the fractions indicated on the elution curve (a). The migration position of $\alpha \mathrm{C}$ chain is designated by the arrowhead.

collagen recovered in the $0.1 \mathrm{M} \mathrm{NaCl}$ precipitate at neutral $\mathrm{pH}$ (see Materials and Methods) is $\mathrm{AB}$ collagen with little contamination of type IV collagen.

\section{Immunochemical Analysis}

Antibodies to $A B$ collagen were raised in immunized rabbits. The anti-AB collagen antibody purified by affinity chromatography showed a titer of $1 / 256$ with the corresponding antigen according to the passive hemagglutination assay, but titers of less than $1 / 2$ with type I, II, III and IV collagens. The anti-AB collagen antibody maintained cross-reactions with $\alpha \mathrm{A}$ and $\alpha$ B-chains with titers of $1 / 32$ and $1 / 64$, respectively (Table 2 ) by hemagglutination test which is contrary to a recent report by Madri and Furthmayr (14). Anti-type IV collagen antibodies used in this study showed a titer of $1 / 1024$ with the corresponding antigen and titers of less than $1 / 2$ with type I, II, III and AB collagens, according to the passive hemagglutination assay (13). The antibodies to AB collagen and type IV collagen were confirmed to be IgG by the double diffusion method (data not shown).

\section{Immunoelectron Microscopic Studies}

Localization of $\mathrm{AB}$ collagen in the bovine lung parenchyma was studied by immunoelectron microscopy using antibodies specific to $\mathrm{AB}$ collagen. No electron-dense reaction products were found in the basement membrane or interstitial matrix of the lung parenchyma. The reaction products were found frequently but exclusively on the surface of varied cells such as endothelial cells of alveolar capillaries (Fig. 3) and pulmonary arterioles (Fig. 4), alveolar epithelial cells (Fig. 5) and ciliated epithelial

Table 2 Passive Hemagglutination Titers of Purified Anti-AB Collagen Rabbit Antibodies for Bovine Type I, $I I, I I, I V$ and $A B$ Collagens

\begin{tabular}{|c|c|c|c|c|c|c|c|}
\hline \multirow[t]{2}{*}{$\begin{array}{l}\text { Antibody } \\
\text { to }\end{array}$} & \multicolumn{7}{|c|}{$\begin{array}{c}\text { Reciprocal titer }\left(-\log _{2}\right) \\
\text { against }\end{array}$} \\
\hline & $\mathrm{AB}$ & A-chain & B-chain & Type I & Type II & Type III & Type IV \\
\hline $\mathrm{AB}$ collagen & 8 & 5 & 6 & $*$ & * & * & * \\
\hline
\end{tabular}




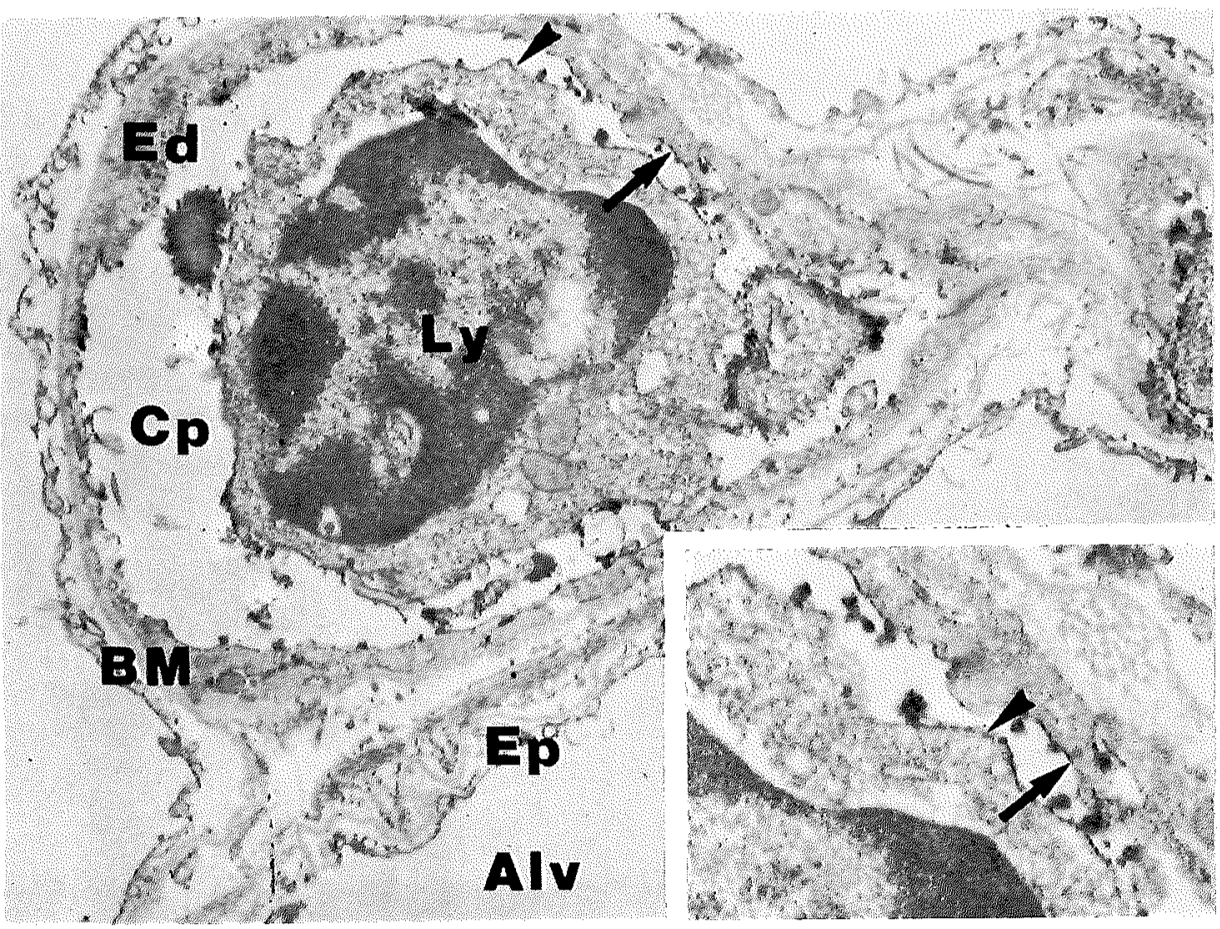

Fig. 3

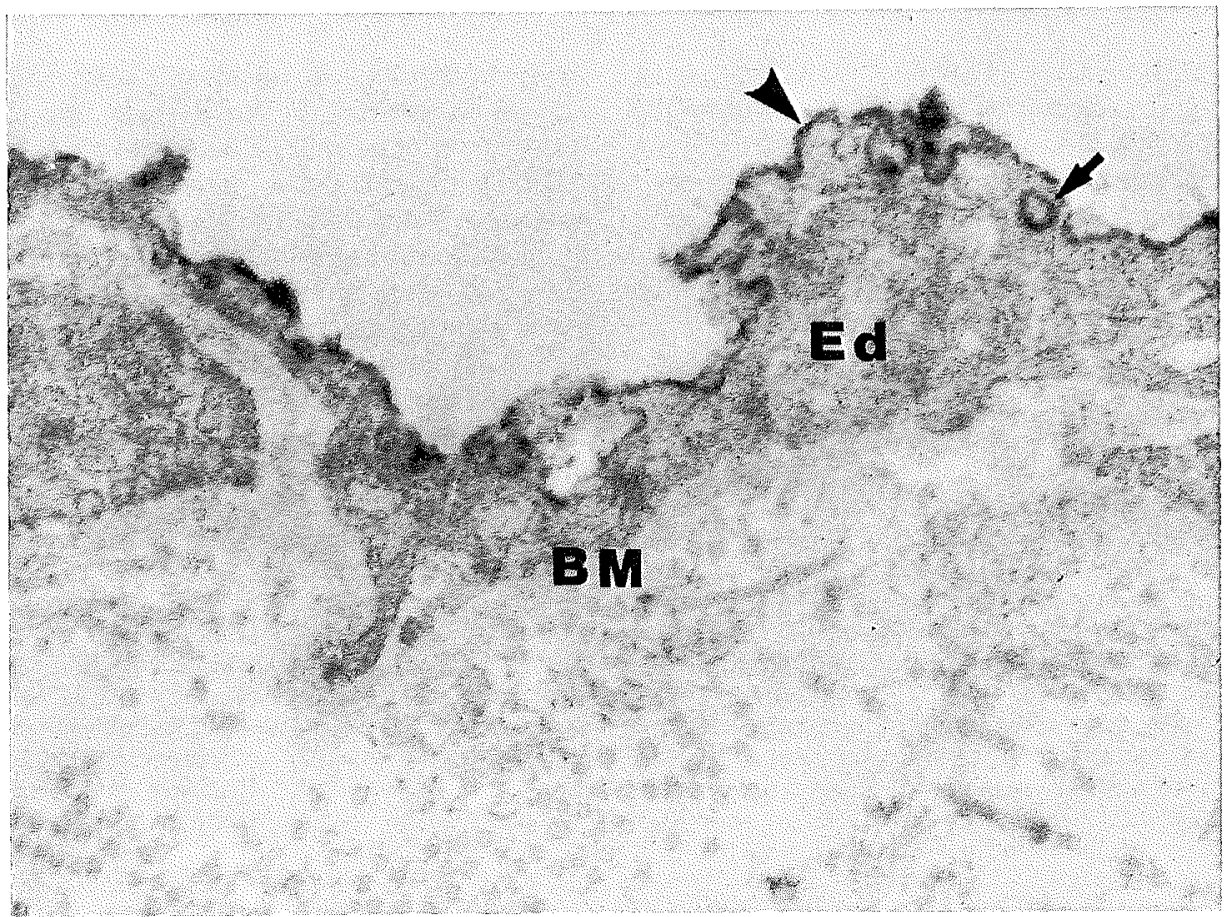

Fig. 4 


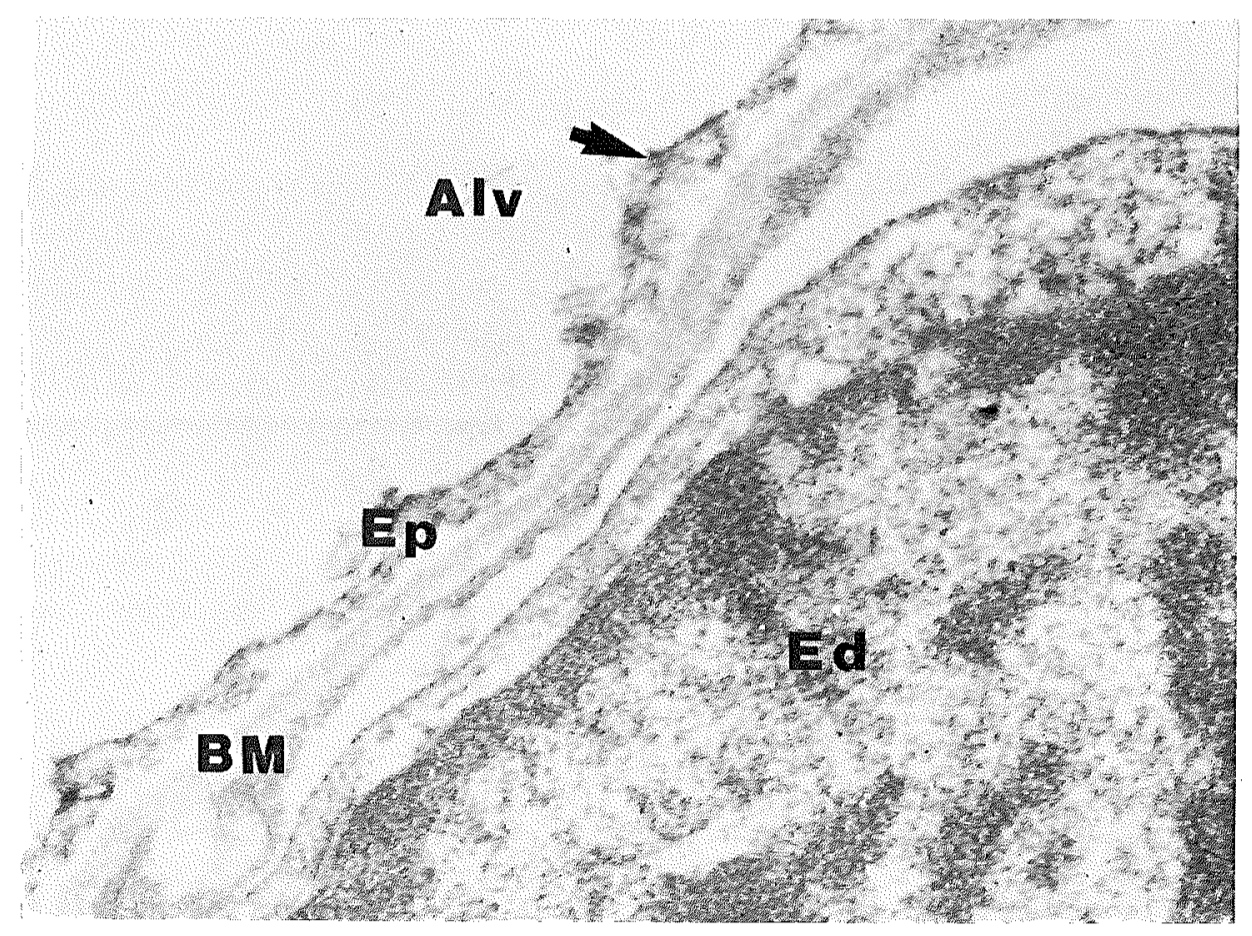

Fig. 5 Electron micrograph of immunoperoxidase reaction in the alveolar wall with uranyl acetate staining. Reaction products with specific anti-AB collagen antibodies are present on the alveolar epithelial cell surface (arrow). Ep, alveolar epithelial cell; Ed, alveolar endothelial cell; Alv, alveolar lumen; BM, basement membrane. $\times 26,000$

cells of bronchioli (Fig. 6), although in most cases, the reaction products were observed on the luminal side of the cell surfaces but scarcely on the basal side. Furthermore, the cell surface of lymphocytes (Fig. 3) and alveolar septal cells (data not shown) as well as the membrane of pinocytotic vesicles (Fig. 4) were also stained.

Fig. 3 Electron micrographs of immunoperoxidase reaction in the alveolar wall of bovine lung with uranyl acetate staining. Electron dense reaction products with specific anti-AB collagen antibodies are present on the cell surfaces of endothelial cells (arrow) and lymphocyte (arrowhead). Ed, capillary endothelial cell; Ep, alveolar epithelial cell; $\mathrm{Cp}$, capillary lumen; Alv, alveolar lumen; BM, basement membrane; Ly, lymphocyte. $\times 11,000$; inset, $\times 19,000$

Fig. 4 Electron micrograph of immunoperoxidase reaction in the intima of the pulmonary arteriole with uranyl acetate staining. Electron dense reaction products with specific anti-AB collagen antibodies are present on the endothelial cell surface (arrowhead) and the membrane of pinocytotic vesicle (arrow). Ed, endothelial cell of arteriole; BM, basement membrane. $\times 39,000$
In control studies, no significant reaction products were detected in the bovine lung tissue incubated with normal rabbit serum or with anti$\mathrm{AB}$ collagen antibodies preincubated with the antigen collagen (data not shown).

When localization of type IV collagen was examined using antibodies specific to the collagen, the electron-dense reaction products were exclusively located along basement membranes of alveoli and capillaries (Figs. 7 and 8), but not on alveolar cells or in the interstitium.

Fig. 6 Electron micrograph of immunoperoxidase reaction in the bronchiolar epithelium with uranyl acetate staining. Reaction products with specific anti-AB collagen antibodies are present on the ciliated epithelial cell surface. Ep, ciliated epithelial cell of bronchiole; $\mathrm{Br}$, bronchiolar lumen. $\times 28,000$

Fig. 7 Electron micrograph of immunoperoxidase reaction in the alveolar wall of bovine lung with uranyl acetate staining. Reaction products with specific anti-type IV collagen antibodies are present along the epithelial and capillary basement membranes. Alv, alveolar lumen; Ed, endothelial cell; $\mathrm{Cp}$, capillary; $\mathrm{BM}$, basement membrane. $\times 7,500$ 


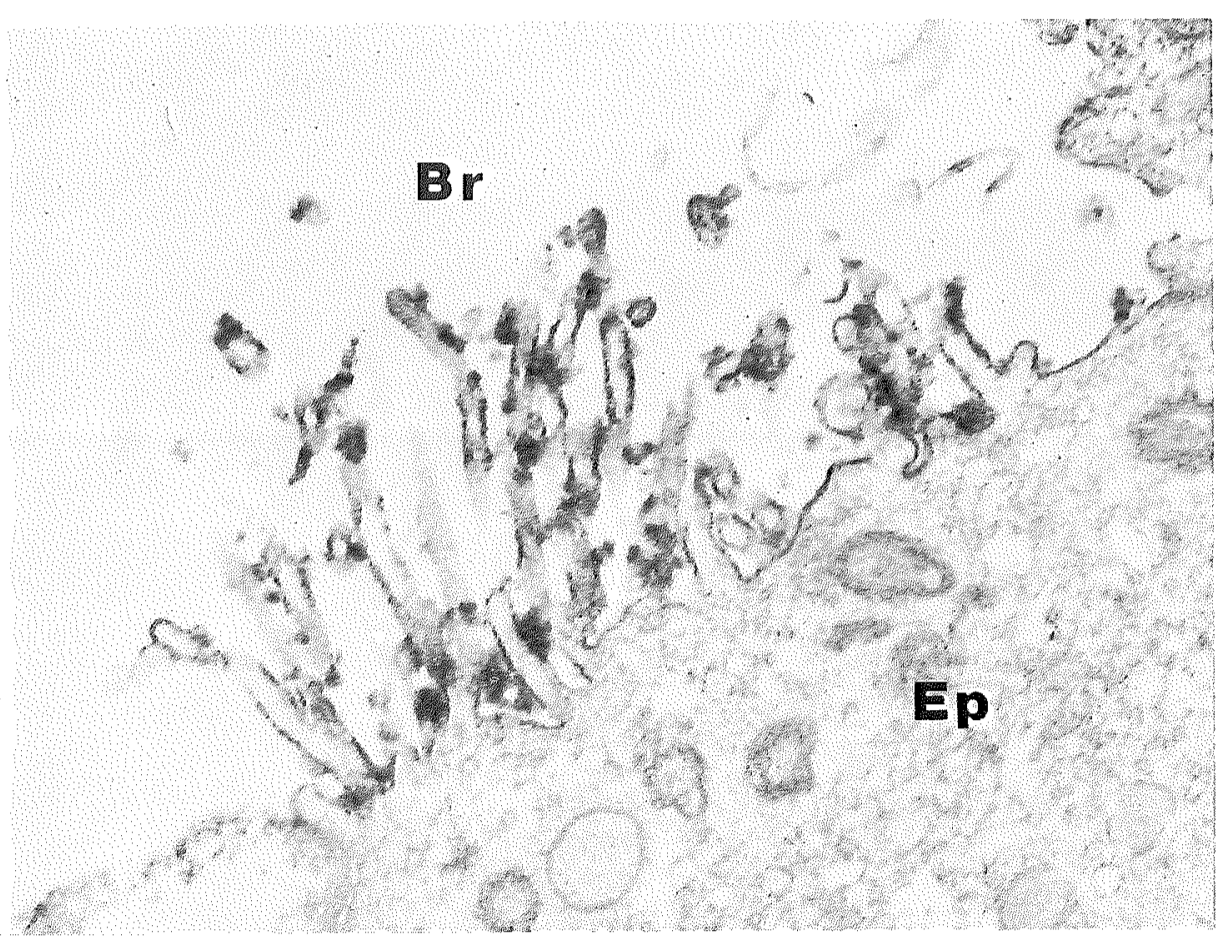

Fig. 6

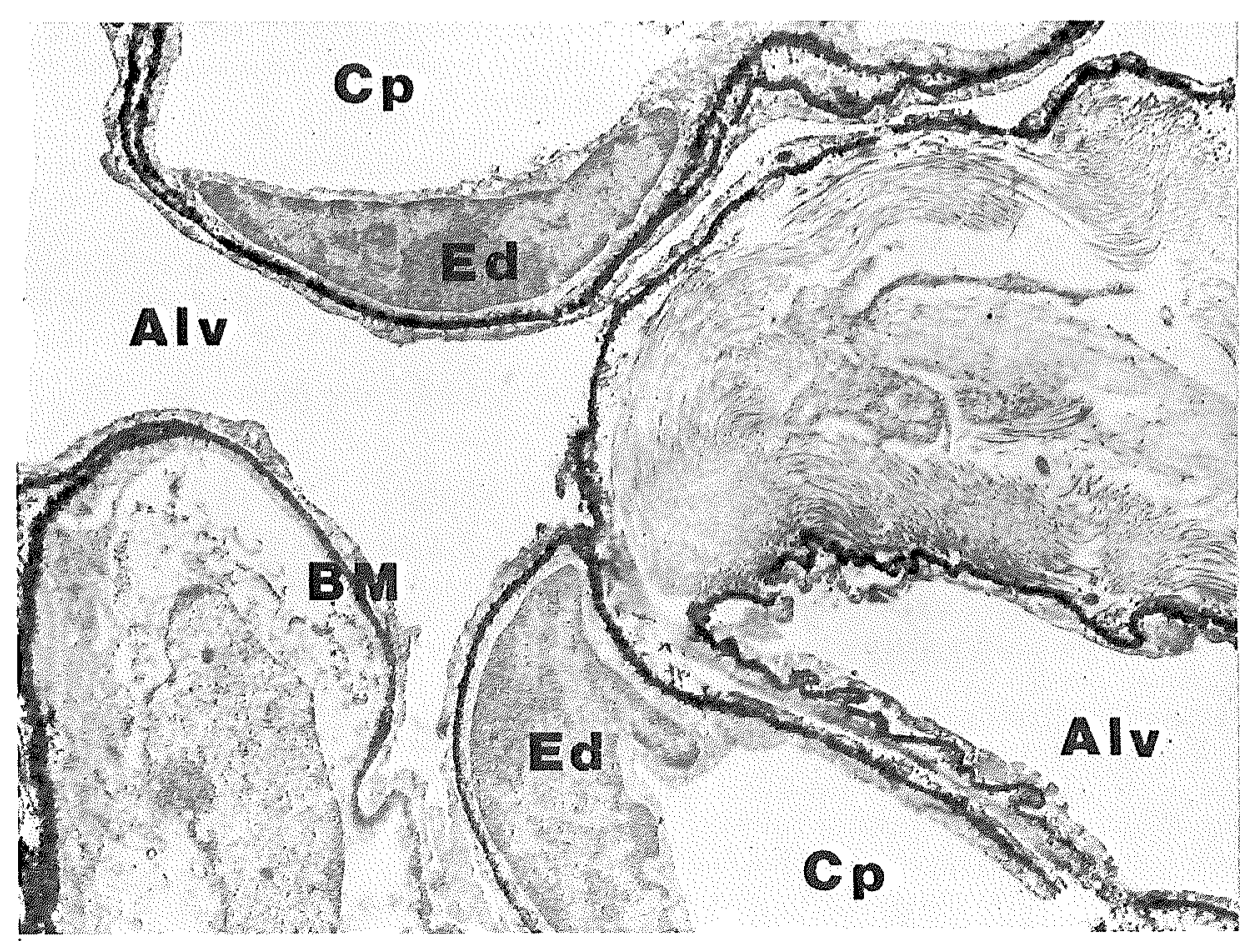

Fig. 7 


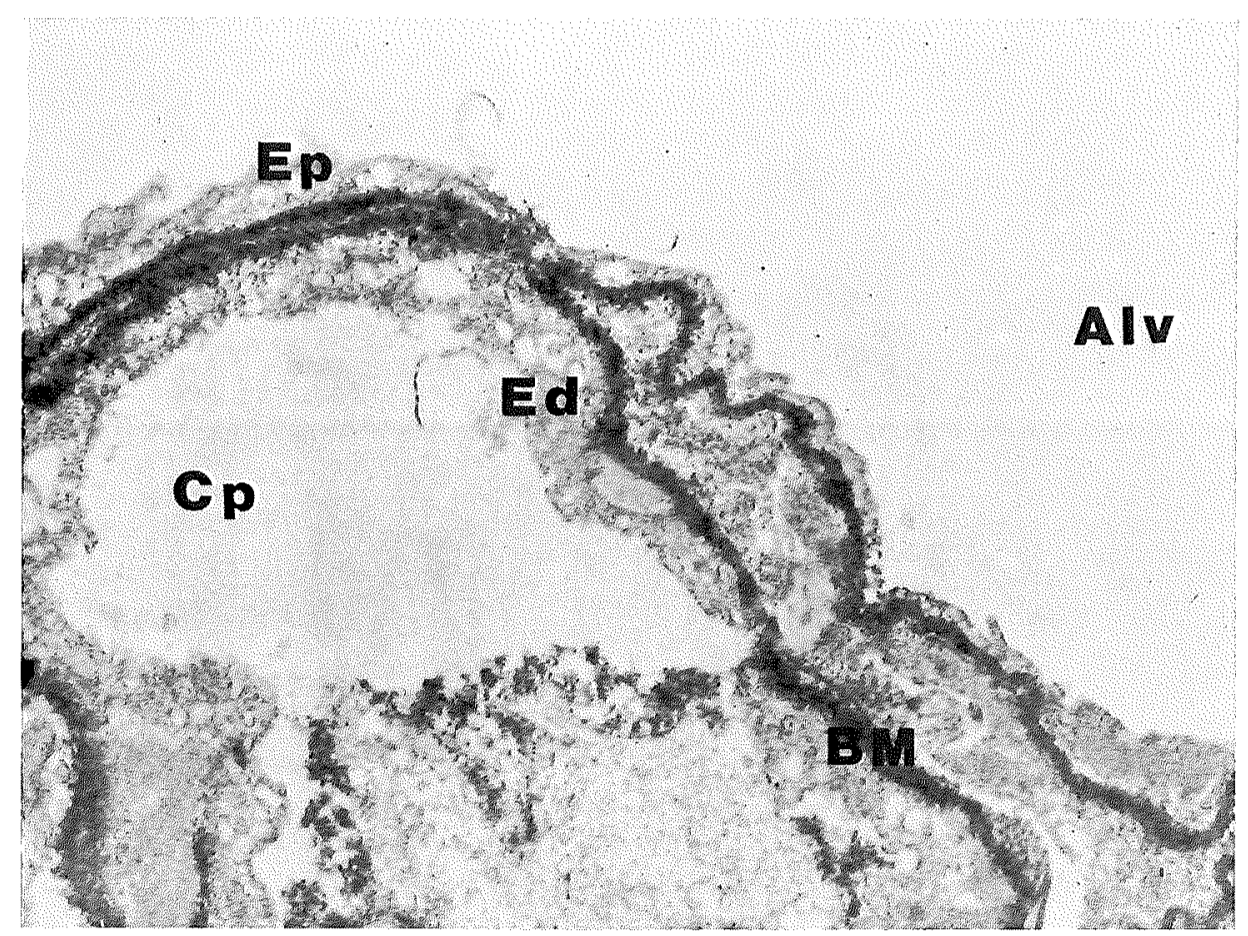

Fig. 8 Electron micrograph of a high magnification of Fig. 7. The reaction products with specific anti-type IV collagen antibodies are exclusively present on the basement membrane. $\times 15,000$

The results described here clearly indicate that the tissue localization of $\mathrm{AB}$ collagen is distinct from that of type IV collagen. Recent reports by Madri et al. described that both $\mathrm{AB}$ and type IV collagens are codistributed along basement membranes of human lungs $(14,15)$ and murine kidneys (23). The discrepancy between their data and ours is difficult to explain. One of the reasons for it might be due to poor permeability of the anti-AB collagen antibodies into the tissue specimens prepared in this study. However, it seems unlikely, since under similar experimental conditions basement membranes were stained with anti-type IV collagen antibodies which showed a titer of the same order as that of the anti-AB collagen antibodies employed. Both antibodies were prepared with the collagens from bovine organs and applied to the tissues from the same animal species.

Taking all the results into account, AB collagen may not be a basement membrane component but a cell-surface-associated component and its frequent but restricted distributions on the outer surface of epithelial and endothelial cells suggest that this collagen may play important roles in cytoskeletal organization and cell migration (25) and differentiation, although the relationship between cell types and physiological functions of $\mathrm{AB}$ collagen remains to be elucidated.

This work was supported in part by Grants from the Intractable Diseases Division, Public Health Bureau, the Ministry of Health and Welfare (Project Team for the Research on Idiopathic Pulmonary Fibrosis and Vascular Lesion of Collagen Disease Research Committee), Japan.

Received for publication 13 November 1980

\section{REFERENCES}

1. Bailey A. J., Shellswell G. B. and Duance V. C. (1979) Identification and change of collagen types in differentiating myoblasts and developing chick muscle. Nature 278, 67-69

2. Beil W., Timpl R. and Furthmayr H. (1973) Conformation dependence of antigenic determinants on the collagen molecule. Immunology 24, 13-24

3. Brown R. A., Shuttleworth C. A. and Weiss J. B. (1978) Three new $\alpha$-chains of collagen from a non-basement membrane source. Biochem. Biophys. Res. Commun. 80, 866-872

4. Burgeson R. E., El Adli F. A., Kaitila I. I. and Hollister D. W. (1976) Fetal membrane 
collagens: Identification of two new collagen alpha chains. Proc. Natl. Acad. Sci. USA $73,2579-2583$

5. Chung E., Rhodes R. K. and Miller E. J. (1976) Isolation of three collagenous components of probable basement membrane origin from several tissues. Biochem. Biophys. Res. Commun. 71, 1167-1174

6. Duance V. C., Restall D. J., Beard H., Bourne F. J. and Bailey A. J. (1977) The location of three collagen types in skeletal muscle. FEBS Lett. 79, 248-252

7. Gay S. and Miller E. J. (1978) Collagen in the Physiology and Pathology of Connective Tissue. Gustav Fischer Verlag, Stuttgart, New York

8. Hayashi T. and Nagai Y. (1979) Separation of the $\alpha$ chains of type I and III collagens by SDS-polyacrylamide gel electrophoresis. $J$. Biochem. 86, 453-459

9. Herbert W. J. (1978) Passive hemagglutination with special reference to tanned cell technique. In Handbook of Experimental Immunology (ed. WeIR D. M.) Third Ed., Chap. 20, Blackwell Scientific Publications, Oxford

10. Hong B. -S., Davison P. F. and Cannon D. J. (1979) Isolation and characterization of a distinct type of collagen from bovine fetal membranes and other tissues. Biochemistry 18, 4278-4282

11. Hori H. and Nagai Y. (1979) Purification of tadpole collagenase and characterization using collagen and synthetic substrates. Biochim. Biophys. Acta 566, 211-221

12. Jimenez S. A., Yankowski R. and Bashey R. I. (1978) Identification of two new collagen $\alpha$-chains in extracts of lathyritic chick embryo tendons. Biochem. Biophys. Res. Commun. 81, 1298-1306

13. Konomi H., Hori H., Sano J., Sunada H., Hata R., Fujiwara S. and NaGai Y. Immunohistochemical localization of type I, II, III and IV collagens in the lung. Acta Pathol. Japon. (in press)

14. Madri J. A. and Furthmayr H. (1979) Isolation and tissue localization of type $\mathrm{AB}_{2}$ collagen from normal lung parenchyma. Am. J. Pathol. 94, 323-330

15. Madri J. A. and Furthmayr H. (1980) Collagen polymorphism in the lung. Human Pathol. 11, 353-366
16. March S. C., Parikh I. and Cuatrecasas P. (1974) A simplified method for cyanogen bromide activation of agarose for affinity chromatography. Anal. Biochem. 60, 149-152

17. McCullagh K. G., Duance V. A. and Bishop K. A. (1979) The distribution of collagen type I, III and $\mathrm{V}(\mathrm{AB})$ in normal and atherosclerotic human aorta. J. Pathol. 130, 45-55

18. Miller E. J., Epstein E. H. and Piez K. A. (1971) Identification of three genetically distinct collagens by cyanogen bromide cleavage of insoluble human skin and cartilage collagen. Biochem. Biophys. Res. Commun. 42, 1024-1029

19. NaGaI Y., Fujiwara S. and HorI H. (1978) Comparison of glomerular basement membrane collagen with interstitial collagens (in Japanese). In Annual Report 1977. Vascular Lesion of Collagen Diseases Research Committee (Chairman: Shiokawa Y.)

20. Peterkofsky B. and Diegelmann R. (1971) Use of a mixture of proteinase-free collagenases for the specific assay of radioactive collagen in the presence of other proteins. Biochemistry 10, 988-994

21. Pöschl A. and VON DER MARK K. (1980) Synthesis of type V collagen by chick corneal fibroblasts in vivo and in vitro. FEBS Lett. 115, 100-104

22. Rhodes R, K. and Miller E. J, (1978) Physicochemical characterization and molecular organization of the collagen A and B chains. Biochemistry 17, 3442-3448

23. Roll F. J., Madri J. A., Albert J. and Furthmayr H. (1980) Codistribution of collagen types IV and $\mathrm{AB}_{2}$ in basement membranes and mesangium of the kidney. J. Cell Biol. 85, 597-616

24. SAge H. and Bornstein P. (1979) Characterization of a novel collagen chain in human placenta and its relation to $\mathrm{AB}$ collagen. Biochemistry 18, 3815-3822

25. Stenn K. S., Madri J. A. and Roll F. J. (1979) Migrating epidermis produces $\mathrm{AB}_{2}$ collagen and requires continual collagen synthesis for movement. Nature 277, 229-232

26. YAmAdA G, and NAKANE P. K. (1977) Hepatitis $\mathrm{B}$ core and surface antigens in liver tissue. Light and electron microscopic localization by the peroxidase-labeled antibody method. Lab. Invest. 36, 649-659 